\title{
Biodegradación de aceite refrigerante (éter bifenilo y bifenilo) en un suelo del orden oxisol en el Municipio Lagunillas del estado Zulia, Venezuela
}

\section{Biodegradation of refrigerant oil (biphenyl and biphenyl ether) in a soil of the oxisol order in Lagunillas Municipality of Zulia state, Venezuela}

\author{
Iván Chirinos $^{1}$ y Iris Betzaida Pérez Almeida ${ }^{2}$ \\ ${ }^{1}$ Universidad del Zulia, Venezuela. \\ ${ }^{2}$ Universidad Ecotec, Ecuador.
}

\begin{abstract}
RESUMEN
Con el fin de evaluar y determinar el tiempo promedio necesario para lograr la degradación total de aceites refrigerantes se realizó un experimento bajo condiciones de invernadero usando como sustrato un suelo del orden oxisol, con $\mathrm{pH}=4,24$ (extremadamente ácido), con alta concentración de aluminio intercambiable $(\mathrm{Al}+3)=1,44 \mathrm{cmol} * \mathrm{Kg}-1$ de suelo, y de textura franco arenosa $(\mathrm{Fa})$, además de abono orgánico en dosis de $20.000 \mathrm{~kg} *$ ha-1. Considerando la condición de acidez del suelo se usó cal agrícola $(\mathrm{CaCO} 3)$ en dosis de $2.144 \mathrm{Kg}$ de carbonato por hectárea. El experimento fue diseñado en factorial 4 x 3 , con 4 tratamientos y 3 repeticiones. Los tratamientos fueron evaluados en maceteros o envases donde se dispuso aproximadamente $0,06 \mathrm{~m} 3$ de la mezcla (suelos + desecho + enmiendas), el desecho o aceite se adicionó en dosis, equivalente a $10 \mathrm{~L} * \mathrm{~m}-2 . \mathrm{El}$ monitoreo se realizó a los 15, 30 y 45 días de incubación. Los resultados obtenidos de tiempo de degradación total de bifenilo (BF) fue de 51 días. En el caso del éter bifenilo (BFE) el tiempo promedio de116 días. Además del tiempo necesario para la degradación, se evaluó población de bacterias del género Pseudomonas, aporte de carbono orgánico y variación de pH del suelo. Según los resultados de este estudio, se puede recomendar la realización de pruebas de campo siguiendo las condiciones de los tratamientos T1 a T3.
\end{abstract}

Palabras clave: degradación, bifenilo, éter bifenilo, oxisol, desecho, biorremediación.

\section{AbSTRACT}

In order to evaluate and determine the average time necessary to achieve the total degradation of refrigerant oils, an experiment was carried out under greenhouse conditions using as substrate a soil of the oxisol order, with $\mathrm{pH}=4.24$ (extremely acidic), with high concentration exchangeable aluminum $(\mathrm{Al}+3)=1.44 \mathrm{cmol} * \mathrm{Kg}-1$ of soil, and sandy loam texture $(\mathrm{Fa})$, in addition to organic fertilizer in doses of $20,000 \mathrm{~kg} *$ ha- 1 . Considering the acidity condition of the soil, agricultural lime $(\mathrm{CaCO} 3)$ was used in doses of 2,144 $\mathrm{kg}$ of carbonate per hectare. The experiment was designed in factorial $4 \times 3$, with 4 
treatments and 3 repetitions. The treatments were evaluated in flowerpots or containers where approximately $0.06 \mathrm{~m} 3$ of the mixture was placed (soil + waste + amendments), the waste or oil was added in doses, equivalent to $10 \mathrm{~L} * \mathrm{~m}-2$. The monitoring was carried out at 15, 30 and 45 days of incubation. The results obtained for the total degradation time of biphenyl (BF) was 51 days. In the case of biphenyl ether (BFE) the average time of 116 days. In addition to the time necessary for degradation, the population of bacteria of the genus Pseudomonas, contribution of organic carbon and variation of soil $\mathrm{pH}$ were evaluated. Based on the results of this study, field tests may be recommended following the conditions of treatments T1 to T3.

Keywords: degradation, biphenyl, biphenyl ether, oxisol, waste, bioremediation.

\section{INTRODUCCIÓN}

$\mathrm{E}^{1}$ l comportamiento de un contaminante en el suelo, así como la efectividad de una tecnología de remediación, están determinados por una variedad de factores que interactúan de manera compleja y que dependen de las características propias del contaminante, así como de las del suelo. Por consiguiente, para la selección adecuada de una tecnología de remediación con buenas perspectivas de éxito, es indispensable considerar tanto las propiedades del contaminante como las del sitio contaminado. En general, dentro de los factores a considerar, se encuentran los siguientes: (i) procesos químicos (reacciones de hidrólisis, oxidación, reducción, fotólisis); (ii) procesos físicos o de transporte (sorción, advección, dispersión, difusión, volatilización y solubilización); y (iii) procesos biológicos (biodegradación, biotransformación y toxicidad), INECC, 2007.

Entre las principales técnicas que se han registrado desde la década de 1970, la biorremediación ha demostrado ser rentable y eficiente en la remoción de determinados contaminantes (Garzón et al. 2017), estos autores demostraron que pesar de los beneficios de las tecnologías de biorremediación, existen algunas dificultades en la aplicación debido a las restricciones impuestas por el sustrato y variabilidad ambiental, el potencial limitado de biodegradación y la viabilidad de los microorganismos de origen natural, entre otras.

En el caso de Venezuela, cuya principal actividad económica o fuente de ingresos lo representa la industria petrolera y petroquímica, es de vital importancia evaluar el impacto que provoca dicha actividad en los ecosistemas, terrestres, acuático y al aire. Para tal fin, se ha implementado la aplicación de la "Ley Orgánica del Ambiente", mediante la cual se regula la generación, manejo, disposición final y tratamiento de los diferentes desechos provenientes de las actividades, de origen industrial.

Esta Ley, contempla la creación de Centros de Manejo de Desechos, destinados a la recepción, manejo, disposición final $y$ tratamiento en suelo de los diferentes residuos generados por las actividades industriales. Las técnicas de tratamiento consideradas en la legislación son: esparcimiento en suelo para lodos y ripios de perforación (base agua), y bío tratamiento para lodos aceitosos y/o desecho industrial de origen orgánico (Decreto 2635que establece la Norma para el Control de la Recuperación de Materiales Peligrosos y el Manejo de los Desechos Peligrosos, Gaceta Oficial N ${ }^{\circ} 5245$ Extraordinario de fecha 3 de agosto de 1998).
En esta región, las actividades petrolera y petroquímica han generado durante décadas una gran cantidad de desechos ricos en hidrocarburos que, de alguna manera han impactado el medio ambiente, provocando deterioro de la flora, fauna y en los recursos hídricos de las zonas adyacentes a los sitios de explotación (Bracho et al, 2004), obligando al establecimiento de Centros de Manejo de Desechos autorizados por el Estado, bajo el cumplimiento de ciertos requisitos, y que han obtenido resultados satisfactorios en tratamiento de dichos de desechos, con un mínimo impacto al ecosistema, empleando la técnica de biorremediación.

Estos Centros de Manejo de Desechos están ubicados en zonas, cuyos suelos poseen condiciones ideales para tal fin como son: baja fertilidad y poca capacidad para el uso agrícola, debido a la condición de acidez que los caracteriza, típicos de las regiones tropicales con períodos definidos de precipitación. Una manera de lograr dicha degradación, bajo condiciones de clima tropical, sería el aprovechamiento de la microflora del suelo (Atlas \& Bartha, 2002). La biodegradación de hidrocarburos por poblaciones nativas de microorganismos representa uno de los mecanismos primarios por el cual los hidrocarburos contaminantes son eliminados del ambiente. Las tasas de degradación bajo condiciones óptimas de laboratorio se encuentran entre 2.500-100.000 g*m-3*día-1, bajo condiciones de campo (in situ) están en un orden de magnitud bajo, en el rango de 0,001-60 g*m-3*día-1 (Atlas, 1981).

Los éteres de bifenilos polibromados (PBDE, por sus siglas en inglés) son un grupo específico de contaminantes emergentes que se caracterizan por ser lipofílicos, hidrofó $\neg$ bicos, bioacumulables y resistentes a la biodegradación. La familia de PBDE consiste de 209 isómeros o congéneres y su estructura química, persistencia y distribución en el ambiente siguen patrones muy similares a los polibromo bifenilos (PBB) y a los poli $\neg$ cloro bifenilos (PCB). El uso principal de los PBDE es como retardantes de flama $\mathrm{y}$ son añadidos a aparatos electrónicos y electrodomésticos, a textiles, muebles, alfombras, materiales de construcción y polímeros (Rocha, G. et al., 2015)

Según Arbeli (2009), la degradación de bifenilo policlorado (PCB) ha sido estudiada ampliamente. Sin embargo, su aplicación en campo es aún muy limitada. La complejidad de la remediación de sitios contaminados con PCB requiere de conocimientos detallados y, por tanto, es necesario seguir investigando y mejorando la bío disponibilidad de PCB, la des halogenación reductiva y el proceso de degradación aeróbica para superar las barreras relacionadas con la biorremediación de sitios contaminados con PCB. 
La eliminación de los bifenilos poli clorados (BPCs) en el medio ambiente depende del grado de cloración del bifenilo. En general, la persistencia de los BPCs aumenta con el grado de cloración (Ruiz et al., 2005). Por las características de estabilidad que presentan los BPCs, resulta difícil su disposición y tratamiento, los procesos utilizados con mayor frecuencia son los métodos físicos (Kaštáneket al., 1995), químicos (Hutzingeret al., 1974), y biológicos (Abramowicz, 1990; Zharikovet al., 2002); de ellos, los de empleo más común son la incineración (Imet al., 2002; Kim et al., 2004b) y la desorción térmica (procesos físicos), este último, utilizado para el tratamiento de suelos contaminados con BPCs (Acharya\& Hay, 2000; Norris et al., 1998; Risoulet al., 2002). Se han aplicado algunos métodos biológicos (biorestauración) a nivel investigación y a escala piloto, resultando en una tecnología potencial, para el mejoramiento del ambiente (Harknesset al., 1993; Zharikovet al., 2002).

Dada la importancia del impacto que provocan los diferentes desechos orgánicos de origen industrial en los ecosistemas, es decir, el proceso de biodegradación de aceites refrigerantes, cuya composición está formada por bifenilo y éter bifenilo, proveniente de la industria petroquímica y que representa un pasivo ambiental importante, este estudio evaluó y determinó el tiempo promedio requerido para lograr la degradación total de los mismos.

\section{Materiales y MÉtodos}

El experimento fue realizado en un invernadero ubicado en departamento de Botánica de la Facultad de Agronomía de La Universidad del Zulia en la ciudad de Maracaibo, Venezuela, empleando un suelo del orden oxisol de textura franco arcillo arenoso (FAa) del Centro de Manejo de Desechos de la Empresa Samfor ubicado en el Danto, municipio Lagunillas, del estado Zulia, Venezuela.

Se controló la temperatura y humedad al invernadero a fin de propiciar las condiciones ideales, para mantener la actividad microbiana en el suelo, acelerando el proceso de degradación del residuo.

Las características climatológicas de la zona donde se ejecutó la investigación son: precipitación media anual de $600 \mathrm{~mm}$, evaporación acumulada de $2.500 \mathrm{~mm}$, temperatura media anual de $28,3{ }^{\circ} \mathrm{C}$ y una radiación solar cercana a 400 $\mathrm{cal}^{*} \mathrm{~m}-2$.

El suelo es ácido $(\mathrm{pH}=4,24)$ con elevada concentración de aluminio intercambiable de $1,44 \mathrm{cmol} * \mathrm{Kg}-1$ de suelo baja capacidad de intercambio catiónico $\left(4,15 \mathrm{cmol}^{* \mathrm{Kg}-1} \mathrm{de}\right.$ suelo) y deficiente en cuanto al contenido de carbono orgánico $(0,59 \%)$, característico de suelos con baja fertilidad química.

Los tratamientos fueron evaluados en maceteros o envases donde se dispuso aproximadamente $0,06 \mathrm{~m} 3$ de la mezcla (suelo + desecho + enmienda). En cada macetero se incorporó el desecho en dosis de $2 \mathrm{~L}$ por macetero, equivalente a 10 $\mathrm{L} * \mathrm{~m}-2$. Las enmiendas fueron aplicadas en dosis de 2.160 $\mathrm{Kg} *$ ha-1, equivalente a $44 \mathrm{~g}$ de cal por macetero, y la materia orgánica en dosis de $20.000 \mathrm{Kg} *$ ha- 1 , equivalente a $400 \mathrm{~g}$ por macetero.

Attribution-NonCommercial 4.0 International (CC BY-NC 4.0)
Dispuestas las mezclas, se procedió a la aireación mediante instrumento manual, para mejorar el suministro de oxígeno y a la irrigación a fin de mantener la humedad adecuada y así evitar el estrés hídrico que podría afectar a los microorganismos.

El experimento fue un diseño factorial $4 \times 3$, es decir, 4 tratamientos (T0, T1, T2, T3), con 3 repeticiones, descritos a continuación:

Tratamiento0: suelo + desecho,

Tratamiento1: suelo + desecho + cal

Tratamiento2: suelo + desecho + materia orgánica

Tratamiento3: suelo + desecho + cal + materia orgánica.

El monitoreo se realizó a los 15, 30 y 45 días luego del inicio de la incubación para su análisis en laboratorio, a fin de determinar concentración de éter bifenílico, bifenilo, población bacteriana (Pseudomonas), carbono orgánico total, y variación de $\mathrm{pH}$.

Los análisis mencionados se realizaron usando la siguiente metodología: $\mathrm{pH}$ en agua en una proporción de 1:2; aluminio intercambiable mediante extracción con cloruro de potasio (KCl) y Capacidad de Intercambio Catiónico (CIC), mediante extracción con acetato de amonio, carbono orgánico usando el método de Walkley Black (vía húmeda) (Methods of Soil Analysis, 1996).

La determinación de la población de Pseudomonas se logró mediante el uso del método de conteo en placa (Niño et al., 2010). La siembra se realizó en agar Cetrimide selectivo para Pseudomonas, por triplicado; luego se incubaron a $32^{\circ} \mathrm{C}$ por 24 horas en una estufa de cultivo, para finalmente realizar el conteo.

Para la determinación de bifenilo y éter bifenilo se empleó la metodología usada y descrita por Zorrilla et al., (2011). La cuantificación de los PCBs mediante cromatógrafo gaseoso Agilent 7890A equipado con un detector de ionización por llama (FID) y una columna de 5\% fenil polixilosano (HP-5) de $30 \mathrm{~m}$ de largo x $320 \mu \mathrm{m}$ de ancho, con un diámetro interior de $0,25 \mu \mathrm{m}$ y se usó hexano como extractor.

Luego de realizar los respectivos muestreos y análisis en laboratorio, la data se recopiló, se ordenó y se procedió a los respectivos análisis estadísticos. En este experimento, la data fue analizada mediante el uso de regresión polinómica para la población de Pseudomonas y lineal en la evaluación de la remoción de bifenilo y éter bifenilo. Con relación al aporte de carbono orgánico, los datos fueron organizados en gráficos, a fin de apreciar su tendencia, y la variación de $\mathrm{pH}$ de igual forma, fue graficada.

\section{ReSUltados}

Los resultados obtenidos en cuanto al comportamiento de la población bacteriana, parámetro importante en la evaluación de la biorremediación, se muestra en la Figura 1.

En el T0, la máxima población de Pseudomonas presentes se alcanzó a los 30 días de iniciado el proceso de incubación. Esto se explica en el hecho de que el carbono contenido en el suelo (bajo), más el aporte por degradación del desecho contribuyen a mantener el suministro de este elemento hasta cierto punto en el cual el proceso de degradación provoca un efecto adverso sobre la población de bacterias, según 
ISSNe: 2617-9156

Siquiera, (1988), se explica por las diferentes transformaciones debido a las reacciones químicas por las que pasan los compuestos orgánicos en el suelo, entre las cuales se conocen: conjugación es cuando el sustrato se torna más complejo por la adición o acomplejamiento con metabolitos microbianos, pudiéndose tornar más recalcitrante y más tóxico y activación, que es la conversión, por acción enzimática, del sustrato no tóxico a una molécula tóxica.

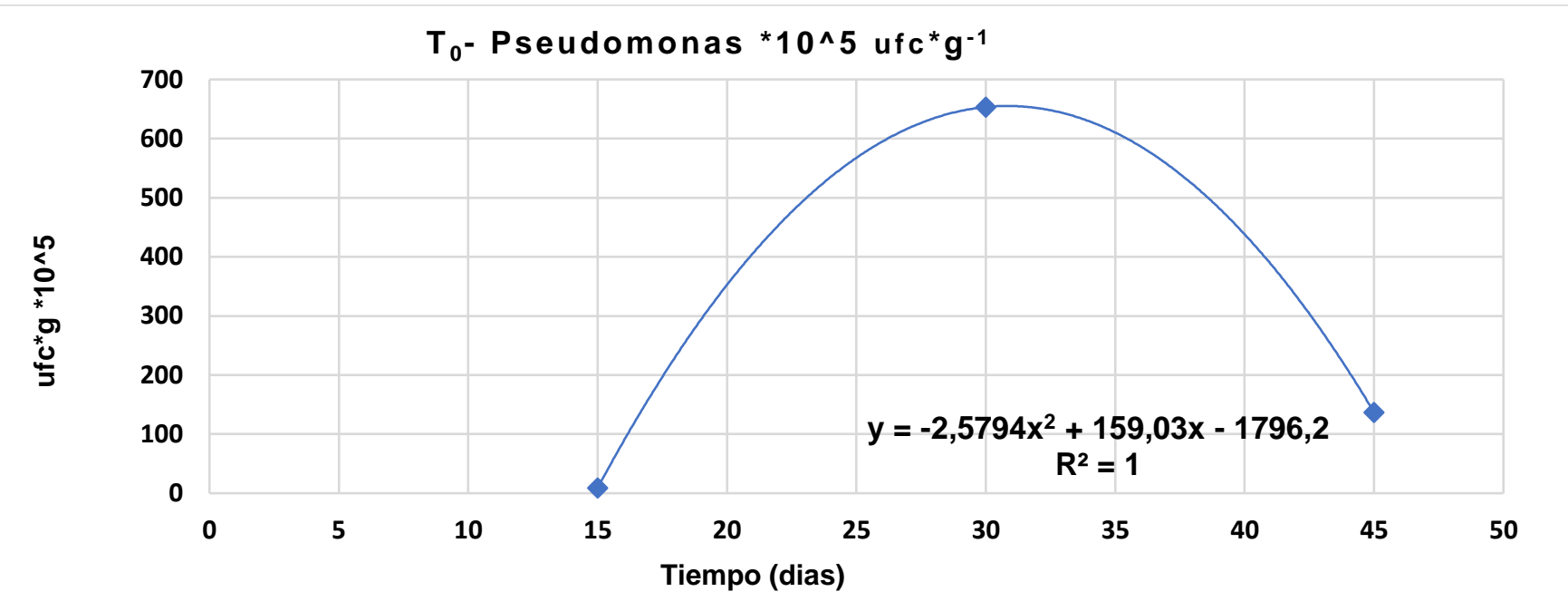

Figura 1.

Población de Pseudomonas (T0) vs. Tiempo de incubación

Estos resultados se ven reflejados también en la Figura 2 en la cual se presenta la misma tendencia, lo que corrobora lo afirmado por Siqueira (1988). Se aprecia en ella que la mayor población se alcanza igualmente a los 30 días de iniciado el experimento. Por otro lado, es importante resaltar que, aunque en T1 se empleó carbonato de calcio para neutralizar la acidez, solo se pudo alcanzar valores de población (90*105 $\left.\mathrm{UFC}^{*} \mathrm{~g}-1\right)$ muy por debajo de los alcanzados en T0 $(650 * 105$ $\left.\mathrm{UFC}^{*} \mathrm{~g}-1\right)$, esto se debe posiblemente al hecho de que la incorporación de carbonato en $\mathrm{T} 1$ provocó un cambio del $\mathrm{pH}$ que inhibió el crecimiento bacteriano.

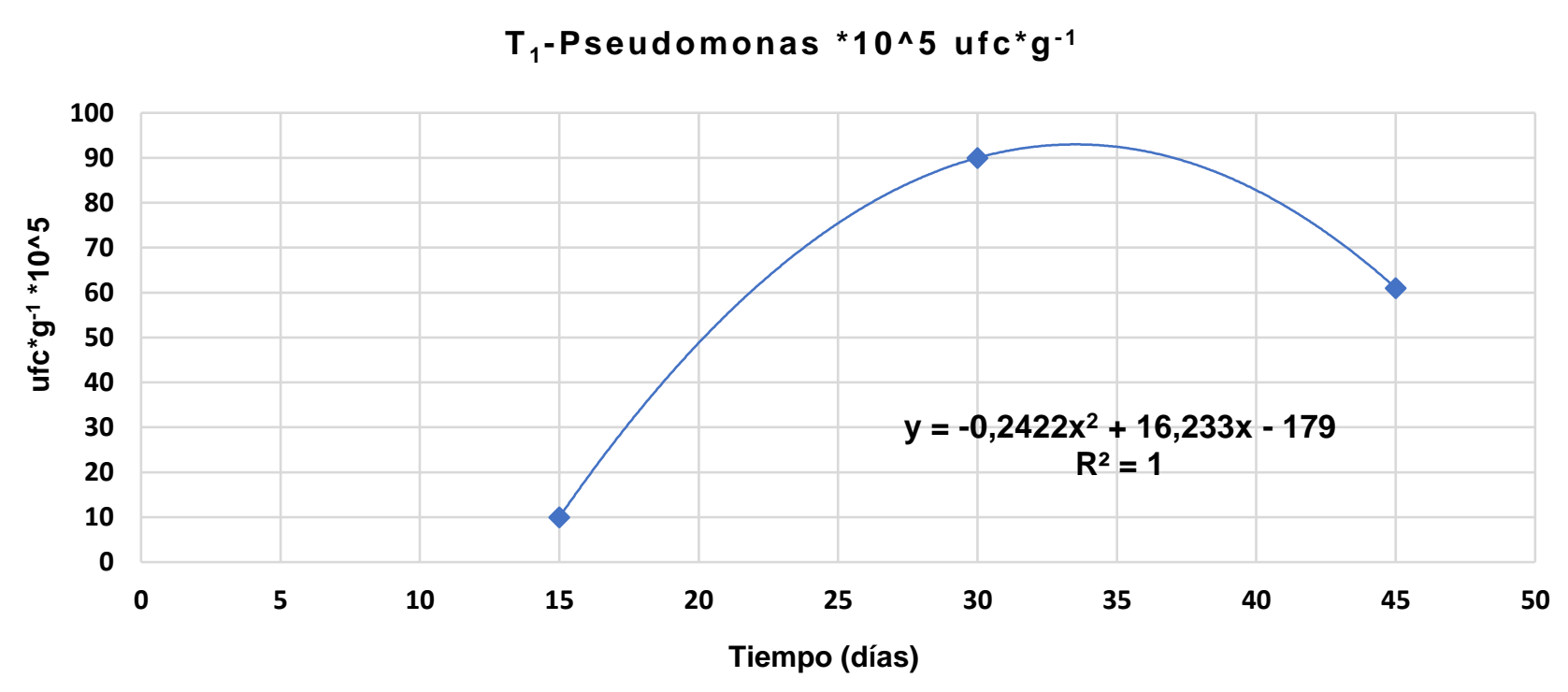

Figura 2.

Población de Pseudomonas (T1) vs. Tiempo de incubación.

Con relación al T2, este mantuvo la misma tendencia, con máxima población $(5.000 * 105$ UFC*g-1) a los 30 días de iniciado el experimento (Fig. 3). Este efecto tiene su explicación en el hecho de que, en este tratamiento, además del desecho se incorporó materia orgánica en la dosis arriba mencionada. Esta incorporación, aunado al carbono aportado por el desecho contribuyó a mejorar la actividad microbiana y consecuentemente al crecimiento poblacional de bacterias Pseudomonas. 


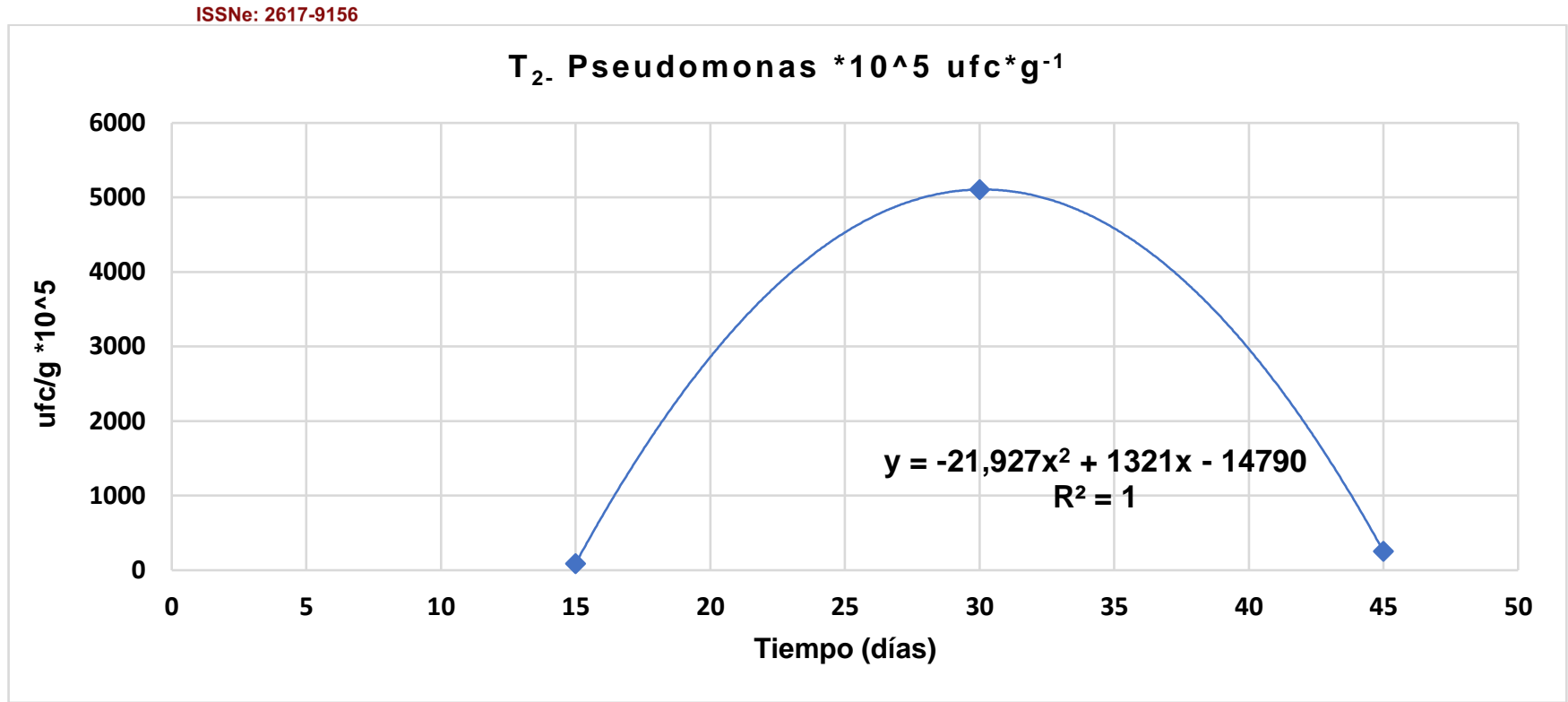

Figura 3.

Población de Pseudomonas (T2) vs. Tiempo de incubación.

La Figura 4 representa la curva de crecimiento de la población de Pseudomonas bajo las condiciones del tratamiento 3 (T3), tendencia similar al resto de los tratamientos, alcanzando un máximo de población de $450 * 105 \mathrm{UFC}^{*} \mathrm{~g}-1$.

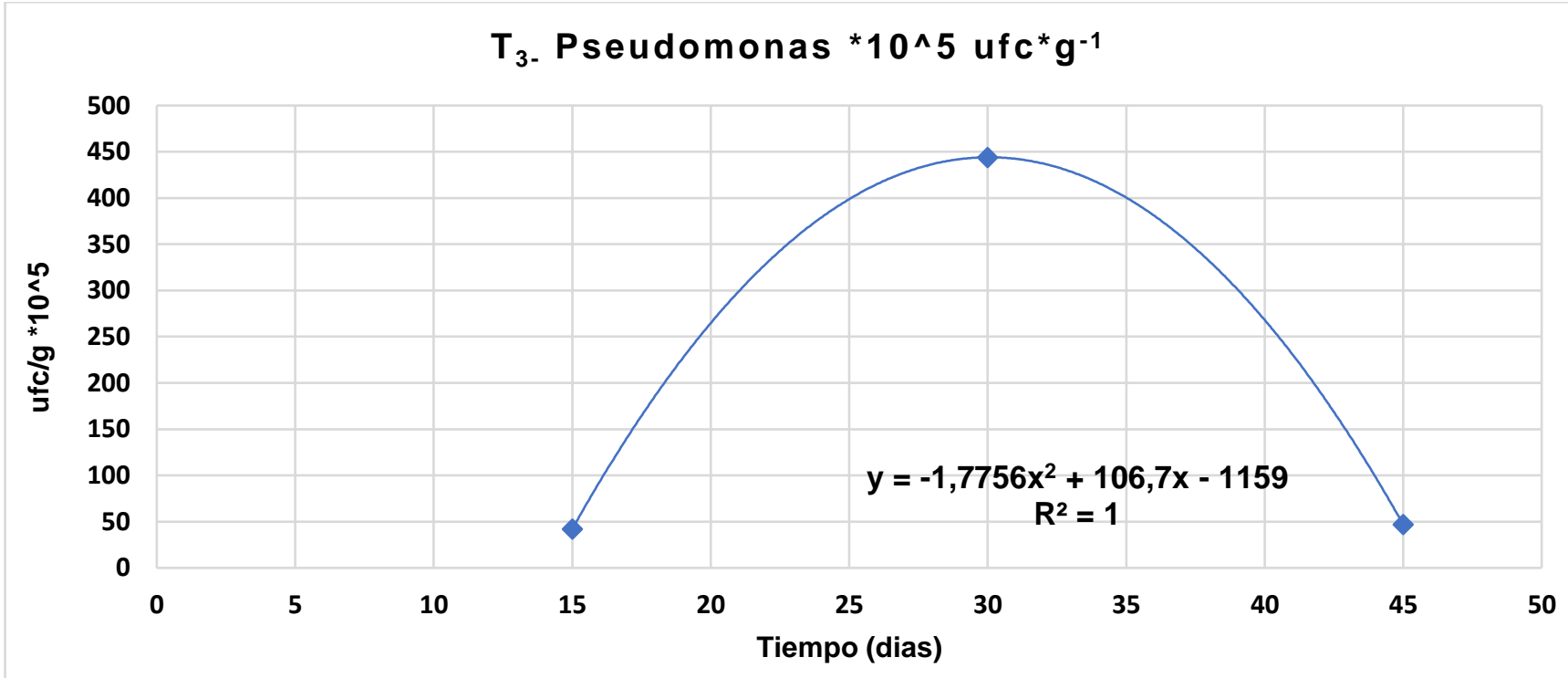

Figura 4.

Población de Pseudomonas (T3) vs. Tiempo de incubación.

A pesar de haber tenido aporte de materia orgánica y carbonato, la población solo alcanzó la décima parte de lo alcanzado en T2, cinco veces la población alcanzada en T1, y ligeramente inferior a la población alcanzada en T0. Estos resultados son similares a los obtenidos por Chirinos et al., (2010), los cuales investigaron en la degradación de lodos petroquímicos ricos en hidrocarburos aromáticos en condiciones de suelos similares. En este caso, el pico máximo de población se registró a los 30 días de iniciado el experimento. En este sentido Pucci, et al.,(2015), determinaron la biodegradación de hidrocarburos en fondos de tanques de la industria petrolera en suelos de la Patagonia, evidenciaron que el sedimento resultante del lavado del fondo de tanque pre $\neg$ sentó una cantidad de bacterias compatibles, cuyo uso es viable en procesos biológicos de degradación. Esta elevada concentración de bacterias con capacidad de degradar hidrocarburos indica un importante potencial de biodegradación.

Por otro lado, Medina et al., (2014), al estudiar la biodegradación de petróleo por microorganismos autóctonos en suelos contaminados provenientes de la bahía de Amuay del estado Falcón, Venezuela, encontraron que las especies de hongos del género Aspergillus aisladas: Aspergillus níger, Aspergillus flavus y Aspergillus terreus, son capaces de crecer y degradar los HTP, observándose una remoción que 
ISSNe: 2617-9156

supera el $85 \%$ de estos contaminantes. Esto corrobora la capacidad degradadora de estos microorganismos y su potencial para ser usados en procesos de remediación de suelos contaminados con petróleo.
Respecto al comportamiento de la reacción del suelo $(\mathrm{pH})$, la Figura 5 muestra las diferentes variaciones de este parámetro durante el período de duración del experimento.

\section{Variación del pH del suelo}

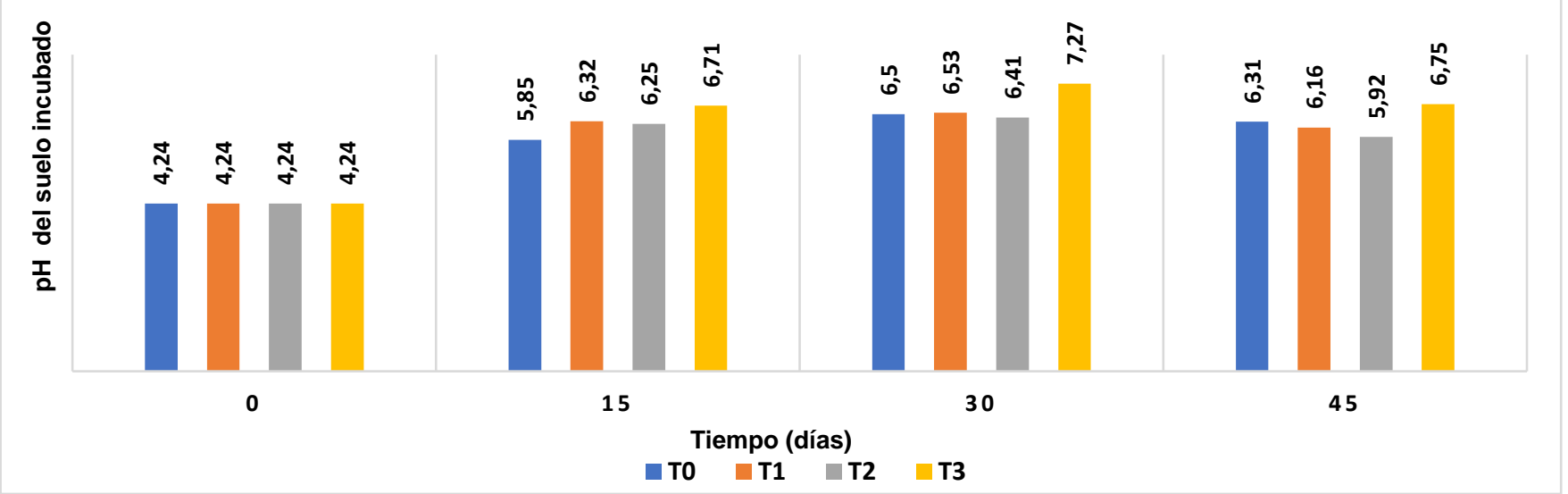

\section{Figura 5.}

Variación del pH del suelo vs tratamiento y tiempo de incubación.

En la Figura 5, se puede apreciar que las diferencias en cuanto a la variación del $\mathrm{pH}$, son relativamente pequeñas, es decir, los diferentes tratamientos tuvieron un efecto similar, a excepción del tiempo cero (0), ya que no ha sido suficiente tiempo para registrarse algún efecto de las enmiendas usadas. Al respecto, Martínez H et al., (2008), reportaron que la materia orgánica del suelo (MOS) afecta la reacción del suelo $(\mathrm{pH})$, debido a los diversos grupos activos que aportan grados de acidez, a las bases de cambio y al contenido de nitrógeno presente en los residuos orgánicos aportados al suelo, (Aguilera, 2000). Wong et al. (2000) incubaron dos suelos, oxisol (4,5\% carbono orgánico) y ultisol (2,6\% de carbono orgánico), con poda de ramillas de árboles observándose durante los primeros 14 días un aumento en $\mathrm{pH}$ de 4,8 a 5,8 en el oxisol y de 4,1 a 6,8 en el ultisol junto a una disminución del aluminio (Al) intercambiable. Para el ultisol el mejor predictor de los cambios de $\mathrm{pH}$ fue el contenido total de bases de las ramillas (calcio, magnesio y potasio).

El aporte de carbono jugó un papel importante en la variación del $\mathrm{pH}$ y el crecimiento poblacional de bacterias Pseudomonas (en este caso como fuente de sustrato). Al respecto, la Figura 6 muestra el comportamiento de esta variable (aporte de carbono orgánico) y su influencia sobre las variables anteriormente mencionadas.

\section{Carbono orgánico total (\%)}

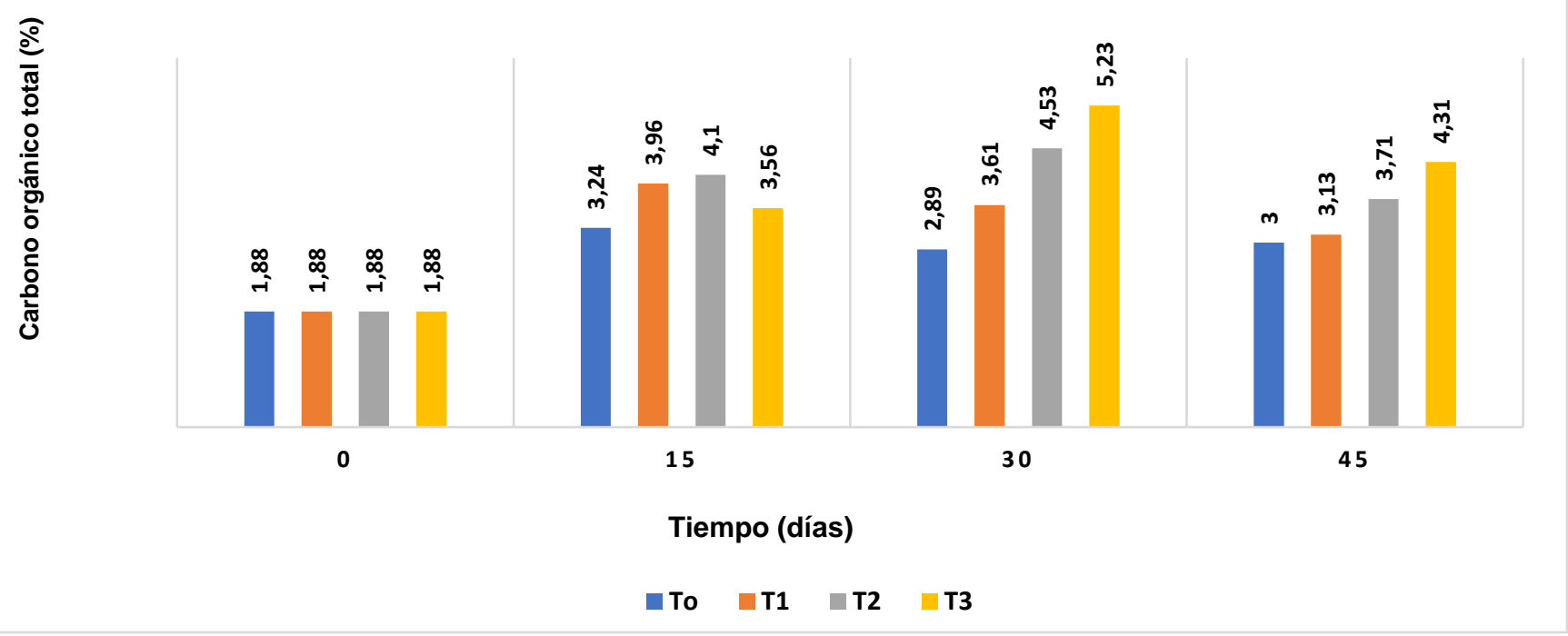

Figura 6.

Carbono orgánico vs. Tratamientos vs. Tiempo de incubación. 
ISSNe: 2617-9156

Esta figura muestra que el mayor aporte de carbono orgánico al suelo, en términos generales ocurrió a los 30 días de iniciado el experimento, especialmente los tratamientos T2 y T3, coincidieron con valores de $\mathrm{pH}$ ideales, lo que a su vez provocó mayor actividad de microorganismos (Fig. 1, 2, 3, y 4).

La degradación de bifenilo y éter bifenilo resultó muy diferente entre ambos compuestos. La Figura 7 muestra que entre 15 y 45 días de incubación, el bifenilo pasa de una concentración de $6.949 \mathrm{mg} * \mathrm{Kg}-1$ a 1.488 mg*Kg-1, lo que representó una remoción del $78,6 \%$ en ese período. La ecuación de regresión lineal obtenida en este caso, con un coeficiente de regresión elevado $(\mathrm{R} 2=0,96)$ indica una alta correlación entre las variables concentración de bifenilo y tiempo para T0.

El modelo de regresión lineal fuey $=-182,04 x+9358$. Esta ecuación permitió determinar de manera muy aproximada el tiempo promedio necesario para degradar completamente el $\mathrm{BF}$, y sería de 51 días aproximadamente.

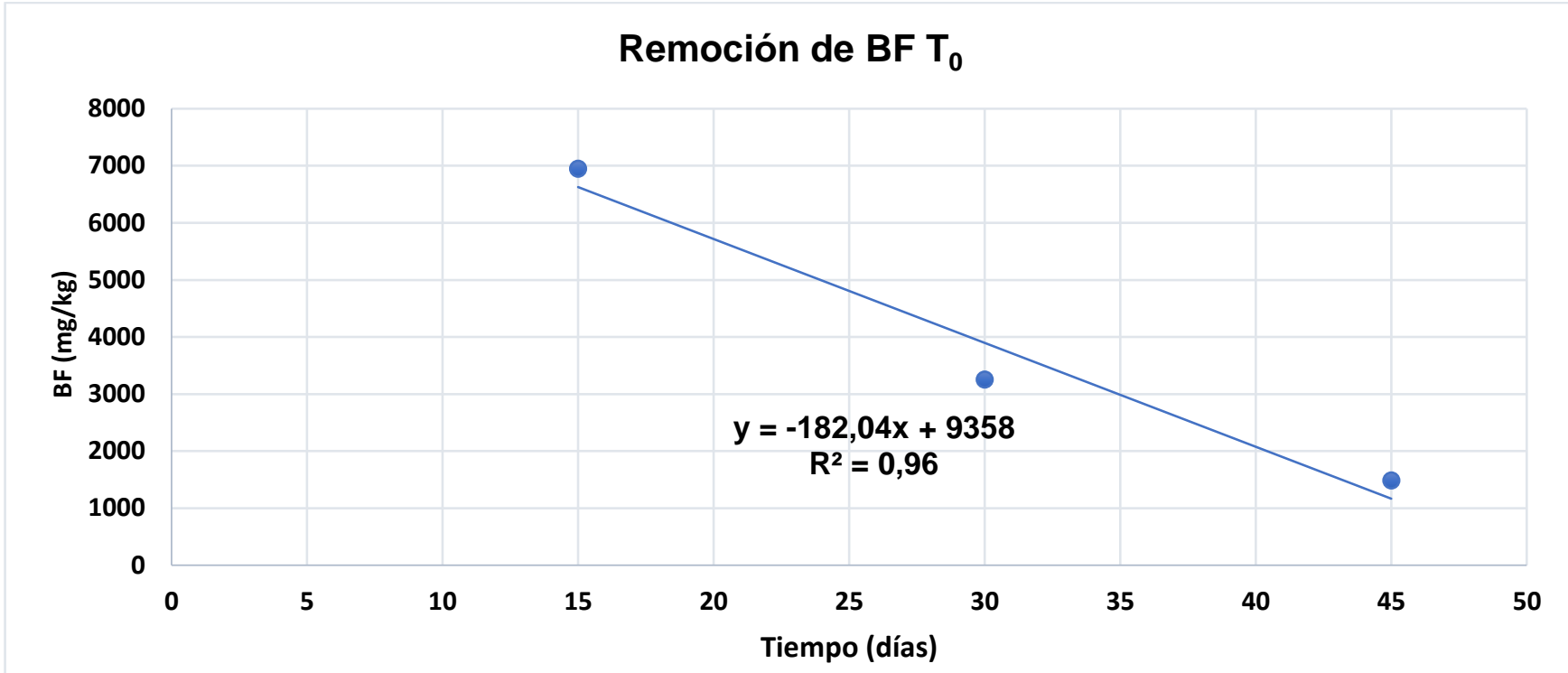

Figura 7.

Remoción de bifenilo (BF) vs. Tiempo de incubación y T0

La Figura 8 muestra que entre 15 y 45 días de incubación el bifenilo pasa de una concentración de $9.038 \mathrm{mg} * \mathrm{Kg}-1 \mathrm{a}$ $1.883 \mathrm{mg} * \mathrm{Kg}-1$, lo que representó una remoción del $79 \%$ en ese período. La ecuación de regresión lineal obtenida $(\mathrm{y}=$ $238.51 x+12418)$ en este caso, con un coeficiente de regresión elevado $(\mathrm{R} 2=0,9909)$ indica una alta correlación entre las variables concentración de bifenilo y tiempo de incubación en T1. Esta permitió calcular el tiempo promedio necesario hasta obtener la remoción total de BF en T1. El tiempo promedio en este caso fue 52 días.

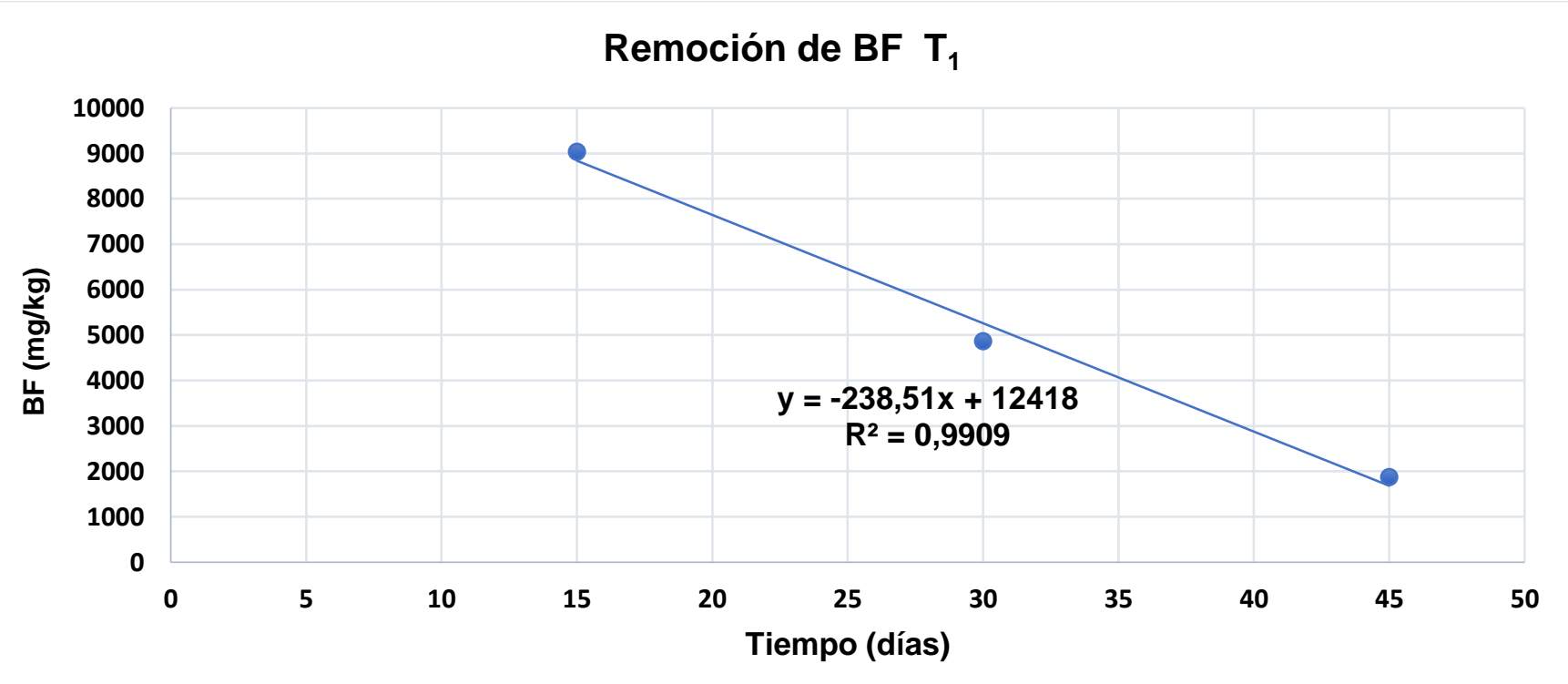

Figura 8.

Remoción de bifenilo (BF) vs. Tiempo de incubación y T1 
ISSNe: 2617-9156

La degradación de BF para T2 está representada en la Figura 9. En ella se determinó que la remoción de BF durante el período comprendido entre 15 y 45 días fue $95 \%$, a pesar de que el coeficiente de regresión fue inferior a los casos anteriores $(\mathrm{R} 2=0,8938)$. La ecuación lineal obtenida para este tratamiento $(\mathrm{y}=-176,55 \mathrm{x}+8753,8)$ permitió ponderar el tiempo necesario para la total degradación en T2 de 50 días.

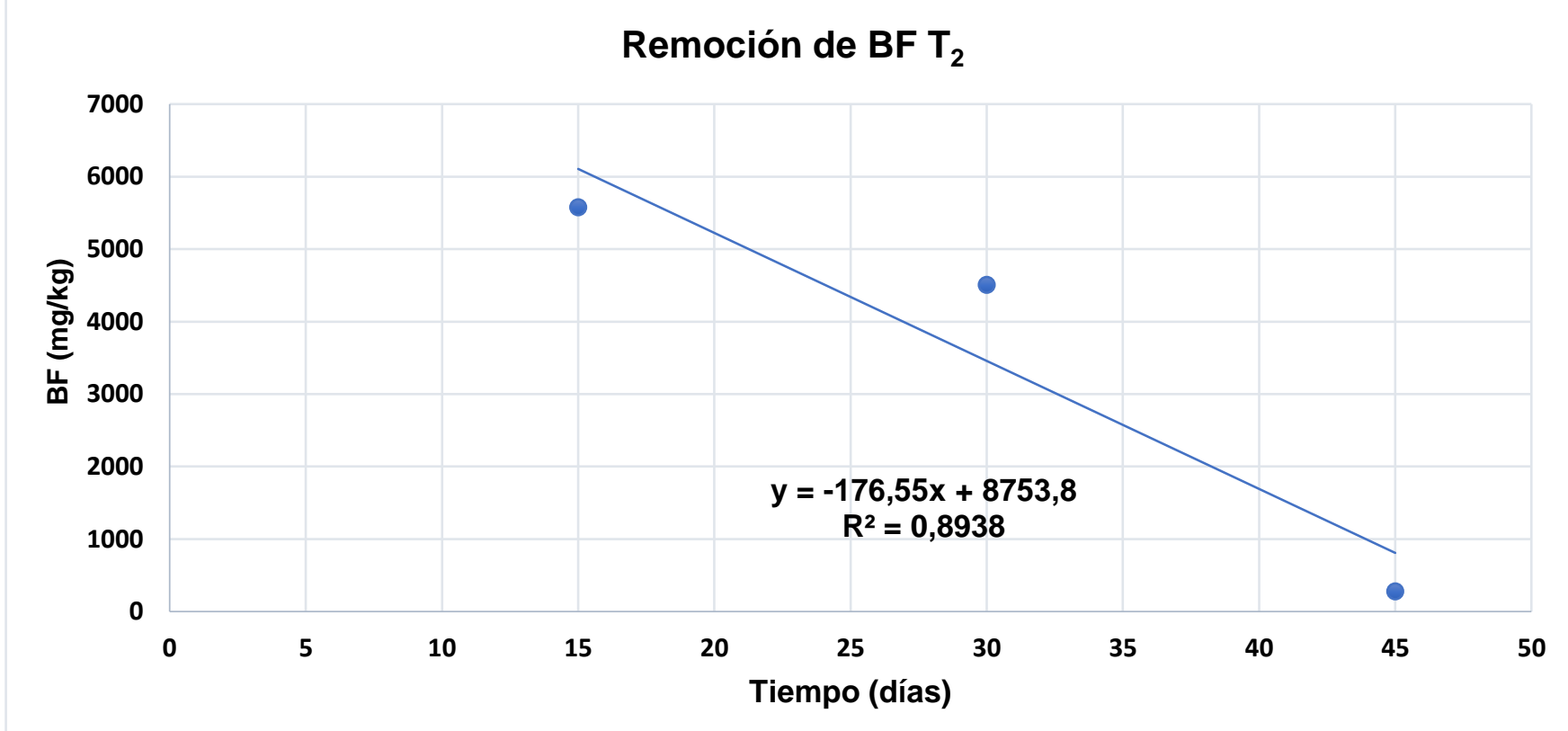

Figura 9.

Remoción de bifenilo (BF) vs. Tiempo de incubación y T2

El T3 tuvo un efecto de remoción del $90 \%$ de BF durante el ensayo (45 días), un coeficiente de regresión elevado $(R 2=0,891)$ y una ecuación de regresión lineal: $y=-198,54 x$
+ 1016, mediante la cual se obtuvo un tiempo requerido para alcanzar la máxima degradación de BF, de aproximadamente 51 días.

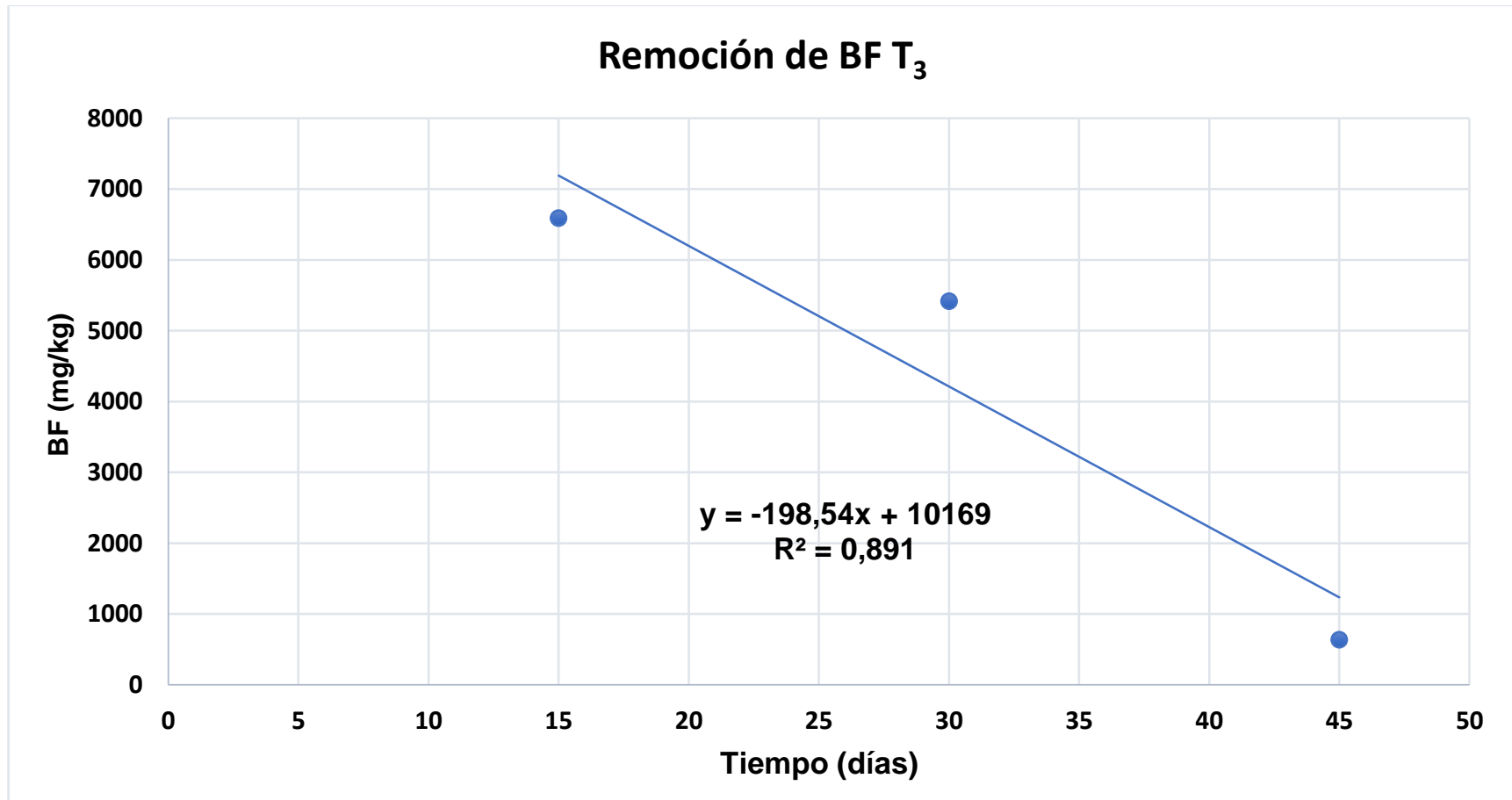

Figura 10.

Remoción de bifenilo (BF) vs. Tiempo de incubación y T3

El éter bifenilo como componente del aceite refrigerante registró un comportamiento similar (T0), con la diferencia de que la remoción del mismo ocurrió de forma más lenta (Fig.11).

https://doi.org/10.46908/tayacaja.v4i2.174 


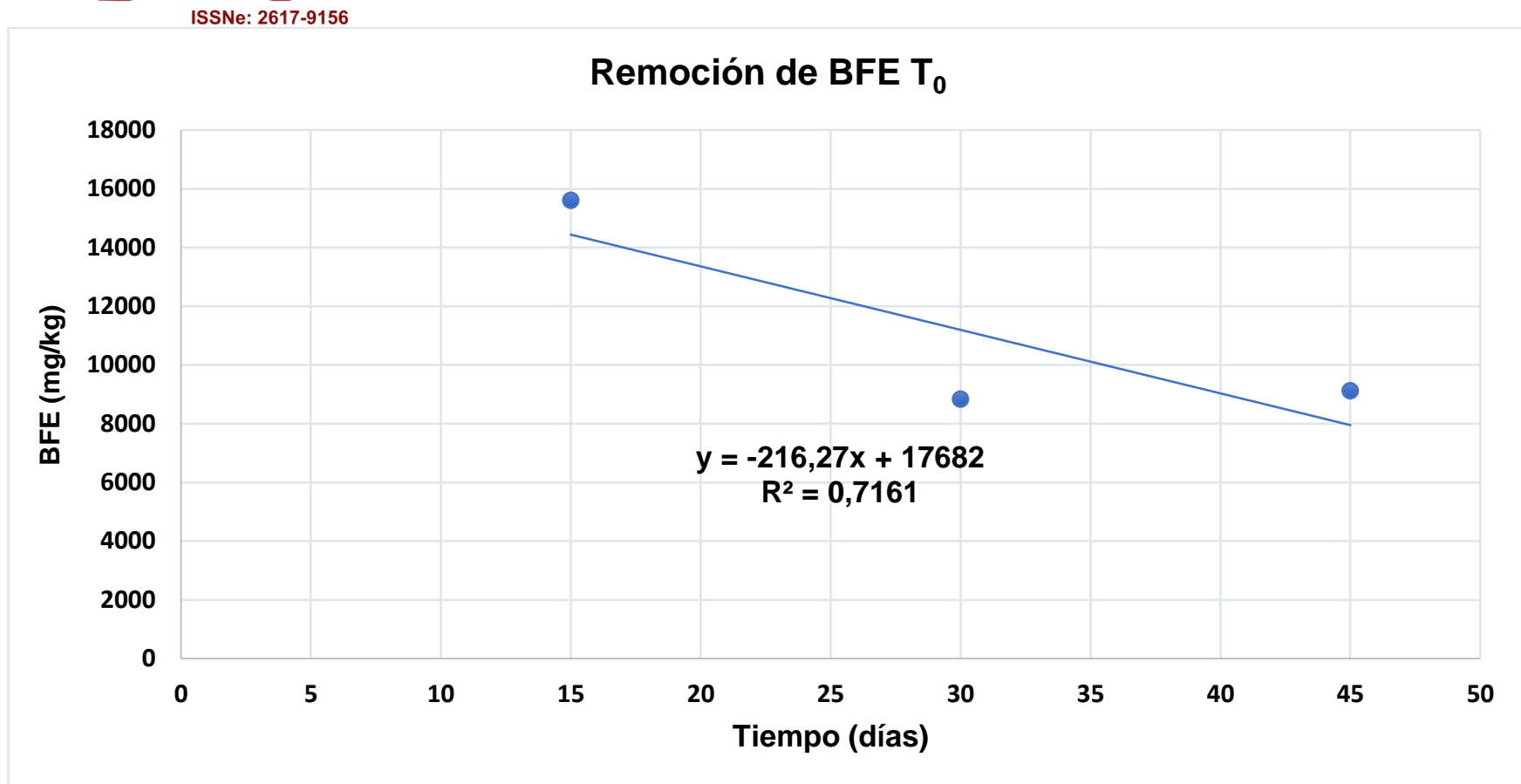

\section{Figura 11.}

Remoción de BFE vs. Tiempo de incubación y T0

En este caso, el \% de remoción entre los 15 y 45 días fue 41,54\%, una ecuación de regresión lineal: $\mathrm{y}=-216,27 \mathrm{x}+$ 17682 y un coeficiente de regresión R2=0,7161. Este modelo de regresión permitió obtener un tiempo necesario para la remoción total del BFE de 82 días para el tratamiento T0.

Para el tratamiento $\mathrm{T} 1$ en la Figura 12 se muestra un comportamiento similar, se obtuvo una remoción de $47 \%$ entre los 15 y 45 días, una ecuación de regresión lineal: y = $299,42 x+22882$ y R2= 0,9303 (elevado), lo que permitió determinar el tiempo promedio de degradación total de este componente en 76 días.

\section{Remoción de BFE $\mathrm{T}_{1}$}

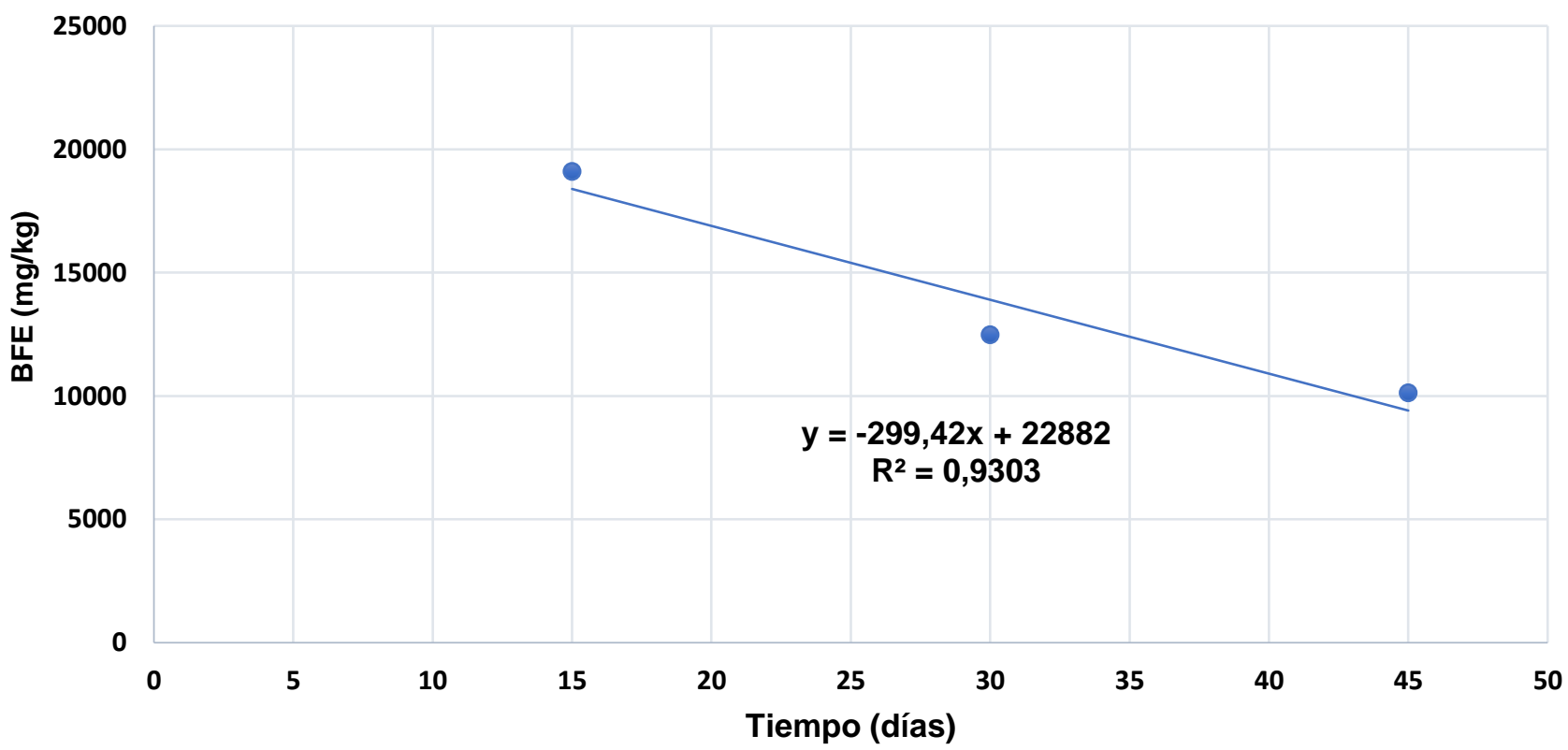

\section{Figura 12.}

Remoción de BFE vs. Tiempo de incubación y T1

La remoción de BFE mediante el T2 fue de 23,20\% bajo si se compara con T0 y T1 (la mitad de lo obtenido en estos), lo que se representa en la Figura 13. La ecuación de regresión: $y=-105,59 x+15586$ permitió estimar el tiempo necesario para la total remoción de BFE y se encontró que en 143 días se puede lograr tal efecto, considerando condiciones de manejo similares. 


\section{Remoción de BFE $\mathrm{T}_{2}$}

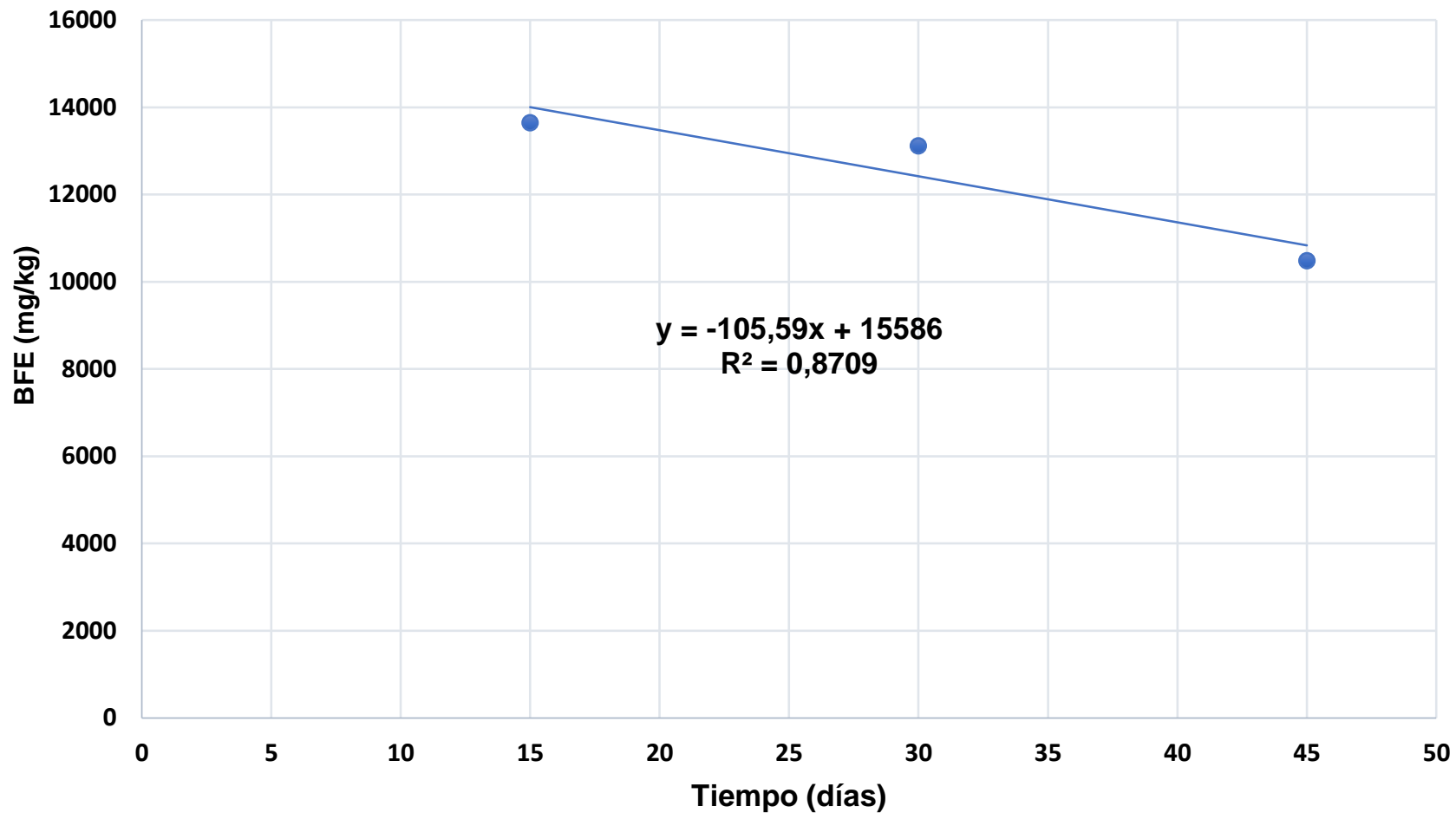

\section{Figura 13.}

Remoción de BFE vs. Tiempo de incubación y T2

Por último, el T3 provocó la remoción de BFE en 21,2\%, bajo, si se consideran los dos tratamientos (T0 y T1).

La Figura 14 muestra la tendencia del modelo de regresión:y $=-104,8 x+17123, R^{2}=0,622$, lo que permitió estimar el tiempo promedio de remoción total del BFE en 163 días.

\section{Remoción de BFE $\mathrm{T}_{3}$}

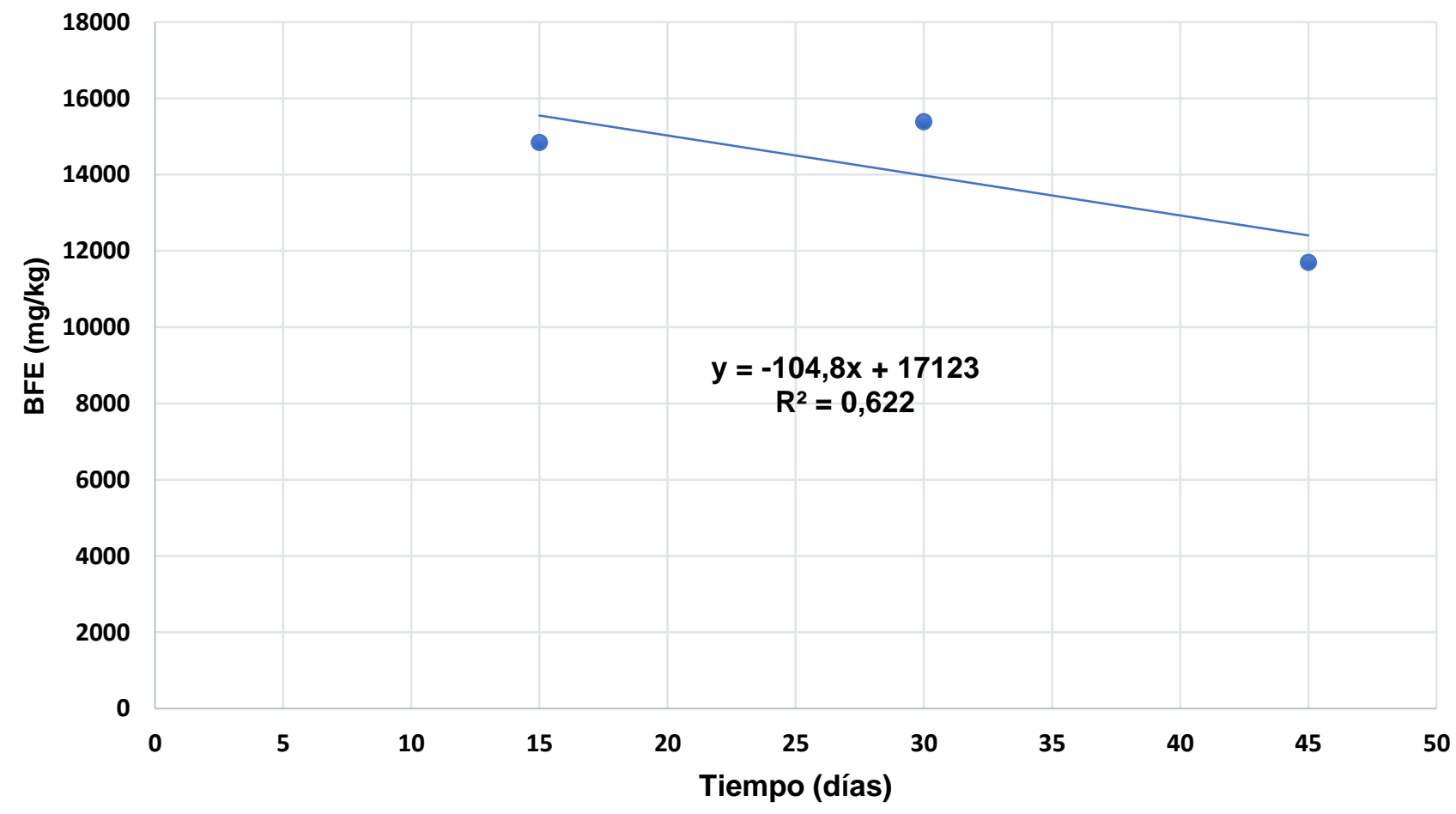

Figura 14.

Remoción de BFE vs. Tiempo de incubación y T3

Attribution-NonCommercial 4.0 International (CC BY-NC 4.0) 
ISSNe: 2617-9156

\section{Conclusiones}

La población de Pseudomonas tuvo un mejor comportamiento bajo condiciones de T2 (suelo + desecho + materia orgánica), el $\mathrm{pH}$ registró mejoras en los tratamientos T1, T2 y T3 y el carbono orgánico alcanzó mejores niveles en el suelo bajo condiciones de los tratamientos T3 (mayor contenido), seguido de T2.

En cuanto a BF se obtuvo una mayor remoción bajo condiciones de T2 y T3 con 90 y $95 \%$ de degradación respectivamente, y tiempos estimados de 50 y 51 para su total remoción. A diferencia de $\mathrm{BF}$, el BFE fue más afectado bajo las condiciones de $\mathrm{T} 0$ y $\mathrm{T} 1$.

Según los resultados de este estudio, se puede recomendar la realización de pruebas de campo siguiendo las condiciones de los tratamientos T1 a T3.

\section{REFERENCIAS}

[1] Abramowicz, D.A. (1990). Aerobic and anaerobic biodegradation of PCBs: A review, Critical Review Biotechnology, 10(3), 241251.https://doi.org/10.3109/07388559009038210

[2] Acharya, P. \& Hay, G.H. (2000). Thermal desorptionthe technology of choice for most soil remediation in 2000 and beyond, Proceedings of the International Conference on Incineration and Thermal Treatment Technologies, Portland, OR, United States, May 8-12, 2000, 588-595.

[3] Aguilera, S.M. (2000). Importancia de la protección de la materia orgánica en suelos. Simposio Proyecto Ley Protección de Suelo. Boletín $\mathrm{N}^{\circ} 14$. Valdivia, Chile, p. 77-85.

[4] Arbeli, Z.(2009). Biodegradación de Compuestos Orgánicos Persistentes (cop): i. el caso de los Bifenilos Policlorados (PCB). Acta Biológica Colombiana, 14(1),57-

88.http://www.scielo.org.co/pdf/abc/v14n1/v14n1a04.p df

[5] Atlas, R. M. (1981). Microbial degradation of petroleum hydrocarbons: an environmental perspective. Microbiological Reviews. 45,(1),180209.https://www.ncbi.nlm.nih.gov/pmc/articles/PMC2 81502/pdf/microrev00009-0186.pdf

[6] Atlas, R. M. \&Bartha, R. (2002). Ecología microbiana y microbiología ambiental. Ed. Addison Wesley. Madrid. $561 \mathrm{p}$.

[7] Bracho, M., Díaz, L.\&Soto, L.M. (2004). Degradación de hidrocarburos aromáticos por bacterias aisladas de suelos contaminados con petróleo en el estado Zulia, Venezuela. Boletín del Centro de Investigaciones $\begin{array}{lll}\text { Biológicas } & 38 & \text { (3): }\end{array}$ https://produccioncientificaluz.org/index.php/boletin/ar ticle/view/31

[8] Chirinos, I., Larreal, M. \& Díaz, J. (2010) Biorremediación de lodos petroquímicos mediante el uso de la biota microbiana autóctona en un oxisol del Municipio Lagunillas del estado Zulia, Venezuela. Revista Científica UDO Agrícola. 10 (1),133140.http://www.bioline.org.br/pdf?cg10018

[9] Garzón, J. M., Rodríguez-Miranda, J.P. \& HernándezGómez, C. (2017). Aporte de la biorremediación para solucionar problemas de contaminación y su relación con el desarrollo sostenible. Universidad y Salud. DOI: http://dx.doi.org/10.22267/rus.171902.93.

[10] Harkness, M.R., McDermott, J.B., Abramowicz, D.A., Salvo, J.J, Flanagan, W.P., Stephens, M.L. et al.(1993). In situ stimulation of aerobic PCB biodegradation in Hudson River sediments, Science 259, 503-507.DOI: $10.1126 /$ science. 8424172

[11] Hutzinger, O., S. Safe, y V.Zitko. (1974). The chemistry of PCBs, CRC Press Inc., USA.

[12] Im, S.H., Kannan, K.,Giesy, J.P., Matsuda, M \& Wakimoto, T. (2002), Concentrations and Profiles of Polychlorinated Dibenzo-p-Dioxins and Dibenzofurans in Soils from Korea, Environmental Science and Technology, 36(17), 3700-3705.Doi: 10.1021/es020531i

[13] INECC. Instituto Nacional de Tecnología y Cambio Climático. Secretaría de Medio Ambiente y Recursos Naturales. Ciudad de México. Factores que inciden en la eficiencia de una tecnología de remediación. 2007.

[14] Kaštánek, F., Kuncová, G., Demnerová, K., Pazlarová., Burkhard, J \& Maléterová, Y.(1995). Laboratory and pilot-scale sorption and biodegradation of polychlorinated biphenyls from ground water, International Biodeterioration and Biodegradation, 287 300.cademia.edu/19211152/Laboratory_and_pilot_scal e_sorption_and_biodegradation_of_polychlorinated_bi phenyls_from_ground_water

[15] Kim, K.S., Hirai, Y., Kato, M., Urano, K \& Masunaga, S.(2004b). Detailed PCB congener patterns in incinerator flue gas and commercial PCB formulations (Kanechlor), Chemosphere, 55(4), 539-553.doi: 10.1016/j.chemosphere.2003.11.056

[16] Martínez H, E., Fuentes E, J.P. \& Acevedo H, E. (2008) Carbono orgánico y propiedades del suelo. Revista de la ciencia del suelo y nutrición vegetal, 8 (1),68-96. https://dx.doi.org/10.4067/S0718-27912008000100006 
ISSNe: 2617-9156

[17] Medina, J., García, F. \& Paricaguán. B. (2014). Biodegradación de petróleo por microorganismos autóctonos en suelos contaminados provenientes de la bahía de Amuay del Estado Falcón. Revista Ingeniería UC, $21 \quad$ (1),6269.https://www.redalyc.org/pdf/707/70732642007.pdf

[18] Niño Camacho, L.\& Torres Sáenz, R. (2010). Implementación de diferentes técnicas analíticas para la determinación de biomasa bacteriana de cepas Pseudomonas putida biodegradadoras de fenol. Revista ION, $23 \quad$ (1), 4146.https://www.redalyc.org/pdf/3420/342030281005.p df

[19] Norris, G., Z. Al-Dhahair, Y J.\& Birnstingl, G.A. (1998). A case study of the remediation of soil contaminated with polychlorinated biphenyls (PCBs) using low temperature thermal desorption, Contaminated Soil '98, Proceedings of the International FZK/TNO Conference on Contaminated Soil, 6th, Edinburgh, May 17-21, 2, 1079-1081.

[20] Pucci, G., Acuña, A \& Pucci. O. (2015).Biodegradación de hidrocarburos en fondos de tanques de la industria petrolera. Revista Peruana de Biología,22(1),97-101. http://www.scielo.org.pe/scielo.php?script=sci_arttext \&pid=S1727-99332015000100006\&lng=es\&tlng=es.

[21] Risoul, V., Renauld, V.,Trouve, G \& Gilot, P.T.(2002). A laboratory pilot study of thermal decontamination of soils polluted by PCBs. Waste Management, 22(1),6172.https://doi.org/10.1016/S0956-053X(01)00051-4

[22] Rocha Gutiérrez, B. A., Peralta Pérez, M.R. \&. Zavala Díaz de la Serna, F.J. (2015). Revisión global de los contaminantes emergentes PBDE y el caso particular de México. Revista Internacional de Contaminación Ambiental, $\quad 31 \quad$ (3),311320.http://www.scielo.org.mx/scielo.php?script=sci_ar ttext\&pid=S018849992015000300010\&lng=es\&tlng=es.

[23] Ruiz-Aguilar, G.M.L. (2005). Biodegradación de Bifenilos Policlorados (BPCs) por microorganismos.Acta Universitaria, 15(2),19-28. doi:10.15174/au.2005.208

[24] Siqueira, J. 1988. Biotecnología do Solo. Editorial Ceres. Brasil. 231 p.

[25] Wong, M., Gibbs, P., Nortcliff, S, Swift, R (2000). Measurement of the acid neutralizing capacity of agroforestry tree prunings added to tropical soils. The Journal of Agricultural Science, 134(3), 269-276. doi:10.1017/S0021859699007388,

[26] Zharikov, G. A., Varenik, V.I.,Borovick, R.V.,Dyadischev, N.R.,Kapranov, V.V., Kiselyova,
N.I. et al. (2002). Ecologically safe technology for bioremediation of soils polluted by toxic chemical substances, NATO Science Series, 1: Disarmament Technologies, 37, 101-186.doi: 10.1007/978-94-0100508-1_17

[27] Zorrilla Velazco, M., Velazco Pedroso, P., Villanueva Ramos, G. \& Vanlangehove, H. (2011). Validación parcial de un método analítico para la determinación de bifenilos policlorados (PCBs) en aceites de transformadores usando la cromatografía gaseosa y Aroclor 1254.Afinidad 68(555),https://raco.cat/index.php/afinidad/article/view /268122. 